\title{
Analysis of the Density of Wooden Components in Ancient Buildings by Micro-Drilling Resistance, Using Information Diffusion
}

\author{
Xin Li, ${ }^{a}$ Wei Qian, ${ }^{b}$, and Lihong Chang ${ }^{c}$ \\ Wooden components were removed from ancient buildings and used as \\ experimental materials. The drilling curve and feed curve were generated \\ from data collected by a resistograph, and the wood density was predicted \\ by using the information diffusion model. A significant correlation was \\ observed between the data for micro-drilling resistance and wood density. \\ The information diffusion methodology was able to predict the wood density \\ by the nonlinear method very well. Using the two-curve effect weight, when \\ the drilling curve data and the feed curve data were 0.2 and 0.8 , respectively, \\ the error was minimum, with an average relative error of $3.82 \%$. Therefore, \\ the data supported on-site ancient building repair work.
}

Keywords: Micro-drilling resistance; Timber structural; Wood density; Information diffusion

Contact information: a: College of Architecture and Art, North China University of Technology, Beijing 100144, China; b: Beijing Engineering Technology Research Center for Historic Building Protection, Beijing University of Technology, Beijing 100022, China; c: College of Urban and Rural Development, Beijing University of Agriculture, Beijing 102206, China;

* Corresponding author: legend622@163.com

\section{INTRODUCTION}

Ancient Chinese buildings consist of timber structures, which contain many valuable historical, scientific, artistic, and social values in their structures and in each of their components (Yang et al. 2012; Liu et al. 2013). Density is one of the important performance indexes of wood, and many mechanical properties of wooden components are correlated with the density of the selected tree species. Therefore, accurately determining the density of wood is an important prerequisite for the protection of ancient building wooden components (Xu 2006; Xu and Qiu 2011; Sun 2012). According to the current Chinese national standard of (GB/T1933 2009), wood needs to be sawn into a standard test size for the traditional density measurement via the volume method. The wood density value obtained by this method is more accurate, but it is not suitable for the testing of ancient building wooden components in use and repair (Fikret and Li 2003). Therefore, obtaining the density information of wooden components by nondestructive (microdestructive) testing is very useful for on-site ancient building repair work.

Currently, micro-drill resistance technology is used to test internal defects and material properties of standing wood and ancient architecture wooden components (An et al. 2008; Gwaze and Stevenson 2008; El-Kassaby et al. 2013). The principle is to drill a probe with a diameter of $1.5 \mathrm{~mm}$ into the interior of a timber at a constant rate to collect the relative resistance value on the test path and present changes in wood density on the test path in the form of a resistance curve. This makes it an intuitive basis for judging internal conditions of the wood section (Huang et al. 2007; Imposa et al. 2014; Newton 2017; Fundova et al. 2018). The micro-drill resistance value has a strong correlation with

Li et al. (2019). "Analysis for density by micro-drilling," BioResources 14(3), 5777-5787. 
the wood dry density measured by the traditional method (Lima et al. 2007; Icel and Guler 2016; Karlinasari et al. 2017). However, the use of wood micro-drill resistance technology to test the mechanical properties of wood has been considered in some studies, and most of them adopt a resistance value as a reference variable for simple linear fitting. Based on this, the IML micro-drilling resistance meter used in this study sets two variables of the probe at constant values, i.e. drilling speed and feed speed (Li et al. 2016), and it collects two sets of parameter data, i.e., drilling relative resistance value $(R)$ and feed relative resistance value $(F)$ as reference variables for data fitting of wood density. Furthermore, a theoretical model of information diffusion to select the above two parameters as input variables to predict wood density was introduced for predicting wood density more accurately and quickly under the conditions of full-scale components on the site.

\section{EXPERIMENTAL}

\section{Test Materials}

The wooden components materials were obtained from the ancient building repair works in Beijing, Shanxi, and Anhui provinces in China. According to the tree species identification form from the Chinese Academy of Forestry Sciences, they were Chinese pine (Pinus tabulaeformis), Simon poplar (Populus simonii Carr), and fir (Cunninghamia lanceolata), as shown in Fig. 1.

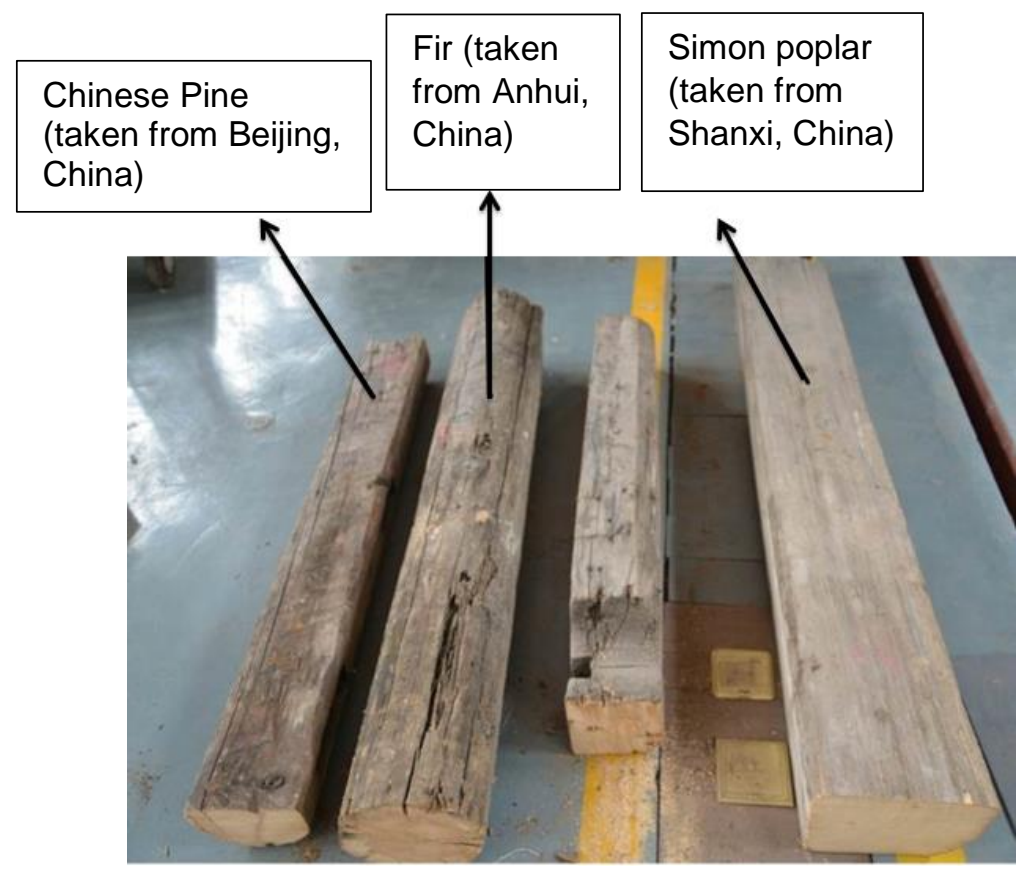

Fig. 1. Test materials selection

According to the national standard on the size requirements for test specimens (GB/T1933 2009), the specimen was sawn along the rift grain direction of the old wooden components to a size of $20 \mathrm{~mm} \times 20 \mathrm{~mm} \times 500 \mathrm{~mm}$ and screened by visual inspection; 10 test specimens without obvious defects were selected for each species.

The test specimens were grouped and numbered, and the water content was balanced to $9 \%$ to $12 \%$ to simulate the general moisture content of wooden components in

Li et al. (2019). "Analysis for density by micro-drilling," BioResources 14(3), 5777-5787. 5778 
the natural environment. Each test specimen was sawn into two parts: Sub-testing Specimen A and Sub-testing Specimen B, whose dimensions were as follows: $20 \mathrm{~mm} \times 20$ $\mathrm{mm} \times 20 \mathrm{~mm}$ for Sub-testing Specimen A, used for data acquisition of air-dry density test; and $20 \mathrm{~mm} \times 20 \mathrm{~mm} \times 480 \mathrm{~mm}$ for Sub-testing Specimen B, used for data acquisition of micro-drill resistance test, as shown in Fig. 2.

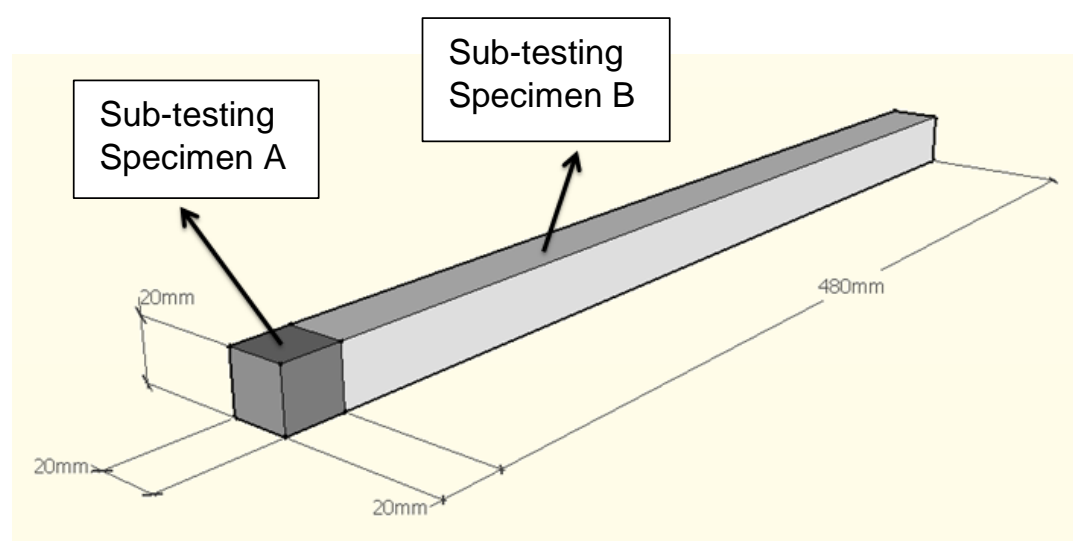

Fig. 2. Dimensions of testing specimens

\section{Air-dry Density Data Collection}

For Sub-testing Specimen A, the volume $(v)$ and mass $(m)$ were measured respectively by the digital vernier caliper (SF2000) (GUANGLU Experimental Instrument Co. Ltd., Guilin, China) and the electronic scale (JJ224BC) (G\&G Measurement Plant, Changshu, China). The air-dry density $(D)$ of the specimen was calculated by the formula, $D=m / v$.

\section{Micro-drill Resistance Data Collection}

The micro-drill resistance data acquisition equipment used in this test was the IML Resistograph PD-Series (IML Co., Ltd., Wiesloch, Germany), as shown in Fig. 3. To avoid accidentality of the test data, the test was designed to uniformly arrange four test points along the rift grain direction of the Sub-testing Specimen B and conduct the micro-drill resistance test perpendicular to the direction of the timer annual rings. The probe drilling parameters were set to $5000 \mathrm{r} \cdot \mathrm{min}^{-1}$ for drilling speed and $200 \mathrm{~cm} \cdot \mathrm{min}^{-1}$ for feed speed. A drilling resistance curve and a feed resistance curve were obtained. Figure 4 is a test curve graph of a certain test point, which represented the relative magnitude of resistance value by an amplitude ratio curve. The arithmetic mean of each resistance curve was taken as the drilling relative resistance value $R_{n}(n=1,2,3$, and 4), and the feed relative resistance value $F_{n}(n=1,2,3$, and 4$)$ of the test point, wherein $R_{n}$ and $F_{n}$ had no units and was expressed with percentage. Through Eq. 1 and Eq. 2, the average value of the data measured by the 4 test points was obtained as the micro-drill drilling relative resistance value $R$ and the micro-drill feed resistance value $F$ of the sub-testing specimen.

$$
R=\frac{\sum_{i=1}^{n} R_{i}}{n}(n=1,2,3,4)
$$




$$
F=\frac{\sum_{i=1}^{n} F_{i}}{n}(n=1,2,3,4)
$$

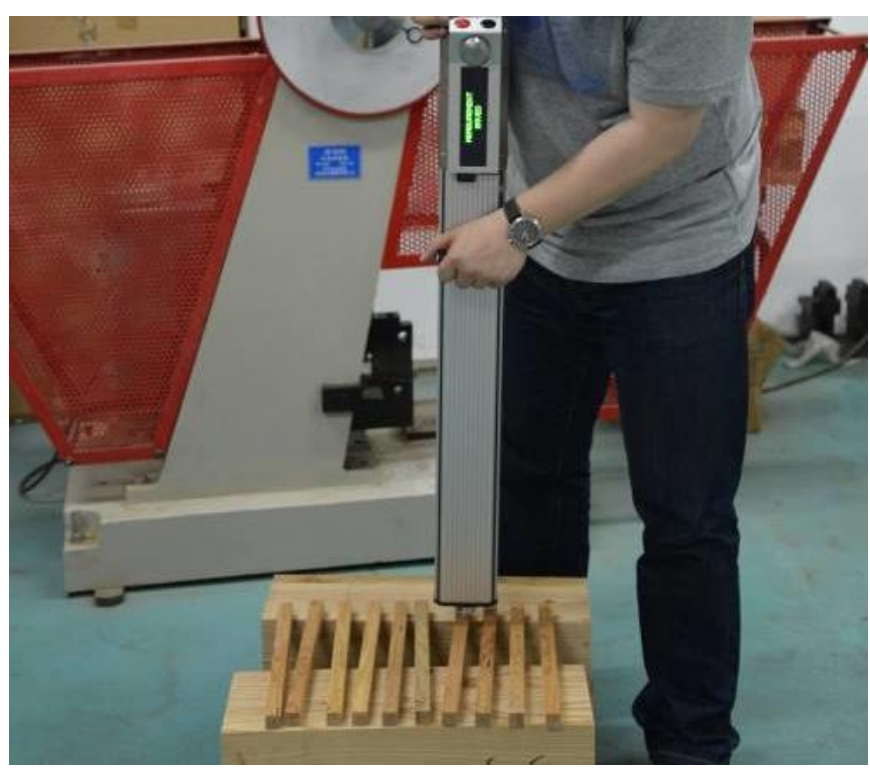

Fig. 3. Micro-drilling resistance test

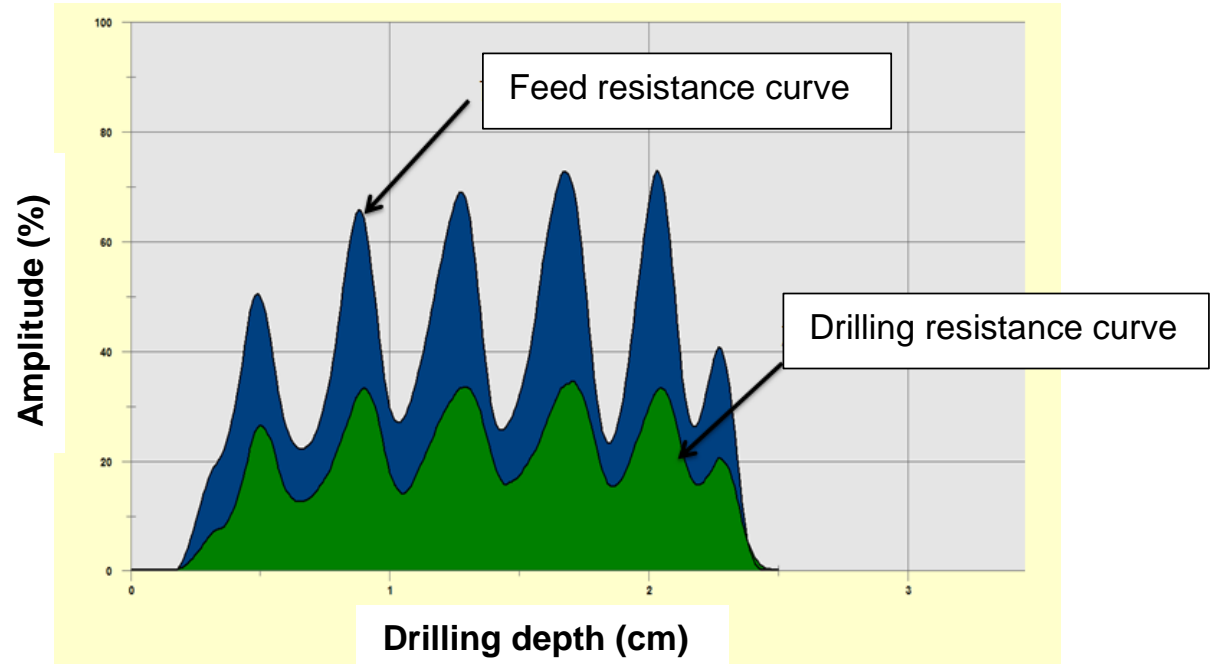

Fig. 4. Example of micro-drilling resistance curve

The results of the two types of test data collected for each tree test specimen are as shown in Table 1. 
Table 1. Data Preparation for Model Building

\begin{tabular}{|c|c|c|c|}
\hline Tree Species & $\begin{array}{c}\text { Drilling Relative } \\
\text { Resistance }(R)(\%)\end{array}$ & $\begin{array}{c}\text { Feed Relative } \\
\text { Resistance }(F)(\%)\end{array}$ & $\begin{array}{l}\text { Wood Density } \\
(D) /\left(\mathrm{g} \cdot \mathrm{cm}^{-3}\right)\end{array}$ \\
\hline \multirow{10}{*}{$\begin{array}{l}\text { Chinese pine } \\
\quad \text { (Pinus } \\
\text { tabulaeformis) }\end{array}$} & 22.385 & 61.875 & 0.683 \\
\hline & 23.105 & 57.717 & 0.686 \\
\hline & 19.979 & 54.987 & 0.650 \\
\hline & 24.030 & 61.192 & 0.693 \\
\hline & 24.159 & 61.518 & 0.708 \\
\hline & 21.499 & 64.412 & 0.680 \\
\hline & 23.581 & 59.086 & 0.690 \\
\hline & 27.129 & 69.345 & 0.723 \\
\hline & 23.973 & 60.462 & 0.696 \\
\hline & 21.521 & 59.890 & 0.668 \\
\hline \multirow{10}{*}{$\begin{array}{l}\text { Simon poplar } \\
\text { (Populus } \\
\text { simonii Carr) }\end{array}$} & 21.200 & 30.660 & 0.430 \\
\hline & 17.241 & 26.134 & 0.405 \\
\hline & 20.600 & 30.447 & 0.431 \\
\hline & 18.031 & 30.112 & 0.405 \\
\hline & 17.744 & 26.834 & 0.400 \\
\hline & 22.483 & 36.604 & 0.460 \\
\hline & 18.049 & 26.443 & 0.399 \\
\hline & 19.170 & 27.345 & 0.401 \\
\hline & 21.311 & 35.644 & 0.444 \\
\hline & 20.241 & 32.704 & 0.427 \\
\hline \multirow{10}{*}{$\begin{array}{c}\text { Fir } \\
\begin{array}{c}\text { (Cunninghamia } \\
\text { lanceolata) }\end{array}\end{array}$} & 12.607 & 17.571 & 0.406 \\
\hline & 20.867 & 23.142 & 0.439 \\
\hline & 17.047 & 18.097 & 0.401 \\
\hline & 19.879 & 23.875 & 0.420 \\
\hline & 10.610 & 18.032 & 0.398 \\
\hline & 11.709 & 17.695 & 0.407 \\
\hline & 20.069 & 23.417 & 0.408 \\
\hline & 15.178 & 20.759 & 0.403 \\
\hline & 17.285 & 17.937 & 0.400 \\
\hline & 11.349 & 17.540 & 0.398 \\
\hline
\end{tabular}

\section{RESULTS AND DISCUSSION}

\section{Information Diffusion Principle}

Information diffusion model is a fuzzy mathematics method established and developed based on the information distribution method. The basic idea is to directly transfer the original information to the fuzzy relationship in a certain way, conduct extremal mathematical processing to samples, and maximize the original information carried by the data, thereby avoiding the gain of membership function (Zhang et al. 2003; Zhu et al. 2011). Therefore, under the condition of incomplete information, the method can predict the relationship between variables by a certain diffusion function from the sample. Information diffusion can be divided into two types: one is to distribute the information of single-valued samples at different control points to achieve data fuzziness; and the other is to gain the information matrix determined by the control points of multiple domains of 
discourse to obtain a fuzzy relationship between them (Li et al. 2014). In this study, the drilling relative resistance value and the feed relative resistance value of the micro-drill resistance meter were the input variables, wood density was the output variable, and the relationship model between the input and output variables was established with the second information diffusion method.

\section{Establishment of Matrix Model}

First, the fuzzy relationship among the drilling relative resistance $(R)$, the feed relative resistance $(F)$, and the wood density $(D)$ was analyzed separately. Taking the drilling relative resistance $(R)$ as an example, as can be seen in Table 1, the numerical range of the drilling relative resistance $(R)$ varied from 10.610 to 27.129 , and the numerical range of the wood density $(D)$ varied from 0.398 to 0.723 . Therefore, the domain of discourse of the two was taken as,

$$
U_{R}=\{9.0,13.5,18.0,22.5,27.0,31.5\} ; \quad V_{D}=\{0.30,0.43,0.56,0.69,0.82\}
$$

where $U$ is the domain of discourse of drilling relative resistance, with a step size $\Delta=4.5$; and $V$ is the domain of discourse of wood density, with a step size $\Delta=0.13$.

This study selected the two-dimensional normal diffusion drop formula:

$$
Q=f_{m}(u, v)=\frac{1}{2 \pi n h^{2}} \sum_{j=1}^{n} \exp \left[-\frac{\left(u^{\prime}-u_{j}^{\prime}\right)^{2}+\left(v^{\prime}-v_{j}^{\prime}\right)^{2}}{2 h^{2}}\right]
$$

where $\quad u^{\prime}=\left(u-a_{1}\right) /\left(b_{1}-a_{1}\right) \quad ; \quad v^{\prime}=\left(v-a_{2}\right) /\left(b_{2}-a_{2}\right) \quad ; \quad u_{j}{ }^{\prime}=\left(u_{j}-a_{1}\right) /\left(b_{1}-a_{1}\right)$; $v_{j}^{\prime}=\left(v_{j}-a_{2}\right) /\left(b_{2}-a_{2}\right) ; \quad a_{1}=\min _{1 \leq j \leq n}\left\{u_{j}\right\} \quad b_{1}=\max _{1 \leq j \leq n}\left\{u_{j}\right\} \quad a_{2}=\min _{1 \leq j \leq n}\left\{v_{j}\right\} \quad b_{2}=\max _{1 \leq j \leq n}\left\{v_{j}\right\}$;

$u_{j}$ and ${ }^{v_{j}}$ are discrete points of $U$ and $V$, respectively. The variable $h=1.4208 /(n-1)$, where $n$ is the number of samples.

According to Eq. 3, the original information distribution matrix $Q_{R, D}$ could be obtained, and then the original information was carried out by normalization processing to obtain the fuzzy relation matrix $T_{R, D}$ between the drilling relative resistance value $(R)$ and the wood density $(D)$. Calculated with MATLAB software (MathWorks, Inc., Natick, MA, USA), the results are shown in Table 2.

Table 2. Initial Information Distribution Matrix $Q_{R, D}$

\begin{tabular}{|l|c|c|c|c|c|}
\hline & $D_{1}(0.30)$ & $D_{2}(0.43)$ & $D_{3}(0.56)$ & $D_{4}(0.69)$ & $D_{5}(0.82)$ \\
\hline$R_{1}(9.0)$ & 0.000 & 0.048 & 0.000 & 0.000 & 0.000 \\
\hline$R_{2}(13.5)$ & 0.000 & 0.524 & 0.000 & 0.000 & 0.000 \\
\hline$R_{3}(18.0)$ & 0.000 & 2.579 & 0.000 & 0.005 & 0.000 \\
\hline$R_{4}(22.5)$ & 0.000 & 1.943 & 0.000 & 6.666 & 0.000 \\
\hline$R_{5}(27.0)$ & 0.000 & 0.000 & 0.000 & 0.262 & 0.000 \\
\hline$R_{6}(31.5)$ & 0.000 & 0.000 & 0.000 & 0.000 & 0.000 \\
\hline
\end{tabular}




$$
T_{R, D}=\left|\begin{array}{lllll}
0.000 & 1.000 & 0.000 & 0.000 & 0.000 \\
0.000 & 1.000 & 0.000 & 0.000 & 0.000 \\
0.000 & 1.000 & 0.000 & 0.002 & 0.000 \\
0.000 & 0.291 & 0.000 & 1.000 & 0.000 \\
0.000 & 0.000 & 0.000 & 1.000 & 0.000 \\
0.000 & 0.000 & 0.000 & 1.000 & 0.000
\end{array}\right|
$$

Similarly, by applying the above equation, the fuzzy relation between the feed resistance value $(F)$ and the wood density $(D)$ of the micro-drill resistance meter could be obtained, and then the original information distribution matrix $Q_{F, D}$ and the fuzzy relation matrix $T_{F, D}$ could be obtained, as shown in Table 3 .

Table 3. Initial Information Distribution Matrix $Q_{F, D}$

\begin{tabular}{|l|c|c|c|c|c|}
\hline & $D_{1}(0.30)$ & $D_{2}(0.43)$ & $D_{3}(0.56)$ & $D_{4}(0.69)$ & $D_{5}(0.82)$ \\
\hline$F_{1}(10)$ & 0.000 & 1.000 & 0.000 & 0.000 & 0.000 \\
\hline$F_{2}(22)$ & 0.000 & 1.000 & 0.000 & 0.000 & 0.000 \\
\hline$F_{3}(34)$ & 0.000 & 1.000 & 0.000 & 0.000 & 0.000 \\
\hline$F_{4}(46)$ & 0.000 & 1.000 & 0.000 & 0.306 & 0.000 \\
\hline$F_{5}(58)$ & 0.000 & 0.000 & 0.000 & 1.000 & 0.000 \\
\hline$F_{6}(70)$ & 0.000 & 0.000 & 0.000 & 1.000 & 0.000 \\
\hline$F_{7}(82)$ & 0.000 & 0.000 & 0.000 & 1.000 & 0.000 \\
\hline
\end{tabular}

$$
T_{F, D}=\left|\begin{array}{lllll}
0.000 & 1.000 & 0.000 & 0.000 & 0.000 \\
0.000 & 1.000 & 0.000 & 0.000 & 0.000 \\
0.000 & 1.000 & 0.000 & 0.000 & 0.000 \\
0.000 & 1.000 & 0.000 & 0.306 & 0.000 \\
0.000 & 0.000 & 0.000 & 1.000 & 0.000 \\
0.000 & 0.000 & 0.000 & 1.000 & 0.000 \\
0.000 & 0.000 & 0.000 & 1.000 & 0.000
\end{array}\right|
$$

\section{Fuzzy Approximate Reasoning}

In the construction of this model, the approximate inference formula,

$$
B_{i}=A_{i} \times R
$$

was used for prediction, where $A_{i}$ in the formula was calculated as follows:

$$
\begin{aligned}
& \text { when } a \leq a_{\text {min }}, a_{\text {min }} \in A_{i}, \quad A_{i}=[1,0, \cdots, 0] \\
& \text { when } a \geq a_{\text {max }}, a_{\text {max }} \in A_{i}, A_{i}=[0,0, \cdots, 1] \\
& \text { when } a_{\text {min }} \leq a \leq a_{\text {max }}, A_{i}=\left[\max \left(0,1-\frac{\left|a-a_{i}\right|}{\Delta}\right)\right] .
\end{aligned}
$$

The above is the first-order fuzzy approximation inference process. If only a single measurement variable is introduced to predict the wood density, the above calculation results are conducted information concentration to obtain the predicted value. In this study, 
the drilling relative resistance and the feed relative resistance of the micro-drill resistance meter have different degrees of influence on wood density prediction. Therefore, the second-order fuzzy approximation inference should be carried out based on comprehensive consideration of the influence weight of each variable. According to Eq. 4, the result of the second-order fuzzy approximation inference can be obtained by the combination operation of Weight Array $A^{\prime}$ and Fuzzy Matrix $R^{\prime}$.

$$
B^{\prime}=A^{\prime} \times R^{\prime}
$$

In Eq. $4, A^{\prime}$ is the influence weight of each variable. In this study, the $A^{\prime}$ value was determined by a cross-combination operation of two measured variables under different influence weights. Upon calculation, when the influence weight of the drilling relative resistance and the feed relative resistance is $A^{\prime}=[0.2,0.8]$, the average relative error of the predicted value is minimal, which is $3.82 \%$.

\section{Information Concentration}

In order to obtain the best predicted value, $B^{\prime}$ is substituted into Eq. 5, and the result is the final predicted value.

$$
D=\frac{\sum_{i=1}^{n}\left(B_{i}^{\prime}\right)^{m} \cdot D_{i}}{\sum_{i=1}^{n}\left(B_{i}^{\prime}\right)^{m}}
$$

where, $D$ is the final predicted value of wood density; $D_{i}$ is the grade value of wood density; $m$ is a constant as appropriate, and $m=2$ in this study.

\section{Analysis}

Table 4 compares the model prediction results and the values measured with conventional methods. Through data analysis, the information diffusion principle can be used to better quantify the testing data of micro-drill resistance and establish its relationship with the wood density value. The method neither needs to know the distribution of the samples nor needs to construct a membership function. The amount of data required is small and the prediction accuracy is high. Under the condition that the influence weight of the two parameters is determined, the minimum average relative error is $3.82 \%$, and the correlation coefficient between the predicted value and the actual value is $\mathrm{R}^{2}=0.990$. Compared with the method of binary linear regression, the calculation error was reduced by 1.26 percent. As far as the tree species data is concerned, it can be found that the bigger the wood density value of a tree species, the smaller the testing error is. For example, the Chinese pine with the highest density's predicted average relative error is $1.45 \%$, while the fir with the lowest density's predicted average relative error is $5.87 \%$.

The larger the density of the tree species, the denser its texture is in the measuring path of the probe. When the probe of a micro-drilling resistance meter drills, subject to the power supplied by a motor, the contact between the wood tissue on the measuring path and the probe is more sufficient, and the feedback effect of the material itself on the probe power output is also more complete and direct; on the contrary, the smaller the density of the tree species, the looser its texture is in the measuring path of the probe when a large amount of wood chips are generated due to the high-speed rotation of the probe. This causes a certain interference to the power output of the probe, thereby affecting accuracy of the measured data. 
Table 4. Contrast of Predicted Value and Measured Value of Wood Density

\begin{tabular}{|c|c|c|c|}
\hline Tree Species & $\begin{array}{l}\text { Actual Value of Wood } \\
\text { Density } /\left(\mathrm{g} \cdot \mathrm{cm}^{-3}\right)\end{array}$ & $\begin{array}{c}\text { Predicted Value of } \\
\text { Wood Density } /\left(\mathrm{g} \cdot \mathrm{cm}^{-3}\right)\end{array}$ & Relative Error \\
\hline \multirow{10}{*}{$\begin{array}{l}\text { Chinese pine } \\
\quad \text { (Pinus } \\
\text { tabulaeformis) }\end{array}$} & 0.683 & 0.689 & 0.008 \\
\hline & 0.686 & 0.689 & 0.004 \\
\hline & 0.650 & 0.646 & 0.006 \\
\hline & 0.693 & 0.690 & 0.005 \\
\hline & 0.708 & 0.690 & 0.026 \\
\hline & 0.680 & 0.688 & 0.011 \\
\hline & 0.690 & 0.689 & 0.001 \\
\hline & 0.723 & 0.690 & 0.045 \\
\hline & 0.696 & 0.690 & 0.009 \\
\hline & 0.668 & 0.688 & 0.030 \\
\hline \multirow{10}{*}{$\begin{array}{l}\text { Simon poplar } \\
\text { (Populus } \\
\text { simonii Carr) }\end{array}$} & 0.430 & 0.436 & 0.015 \\
\hline & 0.405 & 0.430 & 0.062 \\
\hline & 0.431 & 0.434 & 0.008 \\
\hline & 0.405 & 0.430 & 0.062 \\
\hline & 0.400 & 0.430 & 0.076 \\
\hline & 0.460 & 0.451 & 0.020 \\
\hline & 0.399 & 0.430 & 0.077 \\
\hline & 0.401 & 0.431 & 0.074 \\
\hline & 0.444 & 0.440 & 0.008 \\
\hline & 0.427 & 0.433 & 0.014 \\
\hline \multirow{10}{*}{$\begin{array}{c}\text { Fir } \\
\begin{array}{c}\text { (Cunninghamia } \\
\text { lanceolata) }\end{array}\end{array}$} & 0.406 & 0.430 & 0.060 \\
\hline & 0.439 & 0.435 & 0.008 \\
\hline & 0.401 & 0.430 & 0.072 \\
\hline & 0.420 & 0.432 & 0.028 \\
\hline & 0.398 & 0.430 & 0.080 \\
\hline & 0.407 & 0.430 & 0.057 \\
\hline & 0.408 & 0.433 & 0.059 \\
\hline & 0.403 & 0.430 & 0.068 \\
\hline & 0.400 & 0.430 & 0.076 \\
\hline & 0.398 & 0.430 & 0.080 \\
\hline
\end{tabular}

Besides, the Fir has the material characteristics of large differences in heartwood and sapwood density. Therefore, when making standard size specimens, it is bound to cause the dispersion of the data collected among the specimens to be large, thereby increasing the prediction error. However, in general, this method is still an effective method for predicting wood density based on micro-drill resistance data, and the applicability and effectiveness of this method for other different tree species will be further studied.

\section{CONCLUSIONS}

1. Through the micro-drill resistance testing method, information about the internal state of the wood can be obtained quickly and conveniently under the micro-destructive conditions, and a correspondence between the detected value and the density value of the measured wood can be established to provide data support for inferring various

Li et al. (2019). "Analysis for density by micro-drilling," BioResources 14(3), 5777-5787. 5785 
mechanical properties of wood. This method is especially suitable for testing at a protection and repair site of wooden structure historical buildings.

2. With the information diffusion principle to predict wood density, the described method can avoid the gain of membership function. The prediction accuracy and stability are good. The minimum average relative error is only 3.82\%, indicating that the protocol is an effective means and method for predicting the mechanical properties of wooden components with non-destructive testing. It also provides a new idea for the mining application of micro-drill resistance testing data. The principle can determine the influence weight of different measured variables on prediction results. The calculation shows that when the influence weights of the drilling relative resistance value and the feeding relative resistance value are 0.2 and 0.8 , respectively, the predicted relative error against wood density is minimal.

3. Because wood is a anisotropic non-homogeneous biomaterial, the factors affecting its micro-drill resistance testing value are very complex, such as early and late wood, moisture content, nodular scarring distribution, etc. Therefore, under different conditions, the prediction of wood density by micro-drill resistance testing will be further explored.

\section{ACKNOWLEDGMENTS}

The authors are grateful for the support of the Natural Science Foundation of Beijing Municipality (8184068).

\section{REFERENCES CITED}

An, Y., Yin, Y.-F., Jiang, X.-M., and Zhou, Y.-C. (2008). "Inspection of decay distribution in wood column by stress wave and resistograph techniques," Journal of Building Materials 11(4), 457-463. DOI:10.3969/j.issn.1007-9629.2008.04.015

El-Kassaby, Y. A., Mansfield, S., Isik, F., and Stoehr, M. (2013). "In situ wood quality assessment in Douglas-fir,” Tree Genetics \& Genomes 7(3), 553-561. DOI: 10.1007/s11295-010-0355-1

Fikret, I., and Li, B. (2003) "Rapid assessment of wood density of live tree using the resistograph for selection in tree improvement programs," Canadian Journal Forest Research 33(12), 2426-2435. DOI: 10.1139/x03-176

Fundova, I., Funda, T., and Wu, H. X. (2018). "Non-destructive wood density assessment of Scots pine (Pinus sylvestris L.) using resistograph and pilodyn," PLOS One 13(9), e0204518. DOI: 10.1371/journal.pone.0204518

GB/T 1933 (2009). "Method for determination of the density of wood," Standardization Administration of China, Beijing, China.

Gwaze, D., and Stevenson, A. (2008). "Genetic variation of wood density and its relationship with drill resistance in short leaf pine," Southern Journal of Applied Forestry 32(3), 130-133. DOI: 10.2989/SOUTH.FOR.2008.70.2.13.541

Huang, R. F., Wang, X.-H., Li, H., and Liu, X. (2007). "Quantitative analysis on the detected results by resistograph on inside wood decay of ancient architecture," $J$. Beijing Forestry University 29(6), 167-171. DOI: 10.13332/j.1000-1522.2007.06.036

Li et al. (2019). "Analysis for density by micro-drilling," BioResources 14(3), 5777-5787. 5786 
Icel, B., and Guler, G. (2016). "Nondestructive determination of spruce lumber wood density using drilling resistance (resistograph) method," Turkish Journal of Agriculture and Forestry 40(6), 900-907. DOI: 10.3906/tar-1606-76

Imposa, S., Mele, G., Corrao, M., Coco, G., and Battaglia, G.(2014). "Characterization of decay in the wooden roof of the S. Agata church of Ragusa Ibla (Southeastern Sicily) by means of sonic tomography and resistograph penetration tests," Intl. Journal of Architectural Heritage 8(2), 213-223. DOI: 10.1080/15583058.2012.685924

Karlinasari, L., Danu, D., Nandika,D., Tujaman, I. M., Bogor, D., and Ipb, K. (2017). "Drilling resistance method to evaluate density and hardness properties of resinous wood of agarwood (Aquilaria malaccensis)," Wood Research 62(5), 683-690.

Li, B., Ma, D., Su, J., and Wang, W. (2014). "Estimation method for surface rupture width under strong earthquake based on information diffusion," Journal of Basic Science and Engineering 22(2), 294-304. DOI: 10.3969/j.issn.1005-0930.2014.02.010

Li, X., Dai, J., Qian, W., and Chang, L. (2016). "Effect rule of different drill speeds on the wooden micro-drill resistance," Journal of Beijing University of Technology 42(7), 1066-1070. DOI: 10.11936/bjutxb2015060080

Lima, J. T., Sartorio, R. C., Trugilho, P. F., Cruz, C. R., and Vieira, R. S. (2007). "Use of the resistograph for eucalyptus wood basic density and perforation resistance estimative," Scientia Forestalis 35(75), 85-93.

Liu, J., Shen, K., Yu, L., Gao, W., and Gao, X. (2013). "Discussion on structure test technical points for heritage building of timber structure," Building Structure 43(S1), 811-814. DOI: 10.19701/j.jzjg.2013.s1.188

Newton, P. F. (2017). “Acoustic-based non-destructive estimation of wood quality attributes within standing red pine trees," Forests 8(10), 380. DOI: 10.3390/f8100380

Sun, Y., L. (2012). Determining Wood Density and Mechanical Properties of Ancient Architectural Timbers with Micro-Drilling Resistance, Master's Thesis, Beijing University of Forestry, Beijing, China.

Xu, Y. M. (2006). Wood Science, China Forestry, Beijing, China.

$\mathrm{Xu}, \mathrm{M}$., and Qiu, H. (2011). "Experimental study on properties of aged wood of ancient architecture," Earthquake Resistant Engineering and Retrofitting 33(4), 53-55. DOI: 10.3969/j.issn.1002-8412.2011.04.009

Yang, N., Li, P., Law, S. S., and Yang Q. (2012). "Experimental research on mechanical properties of timber in ancient Tibetan building," Journal of Materials in Civil Engineering 24(6), 635-643. DOI: 10.1061/(ASCE)MT.1943-5533.0000438

Zhang, Y., Zhao, C., Ma, B., Sun, Y., and Chen, Z. (2003). "Estimation of distributing rates of the intercity railroad passenger flows based on information diffusion," Journal of Northern Jiaotong University 27(5), 51-54. DOI: 10.3969/j.issn.16730291.2003.05.012

Zhu, Z., Chen, L., Zhang, J., Pan, Y., and Zhu, W. (2011). "Winter wheat yield estimation model based on information diffusion and remote sensing data at major growth stages," Transactions of the Chinese Society of Agricultural Engineering 27(2), 187-193. DOI: 10.3969/j.issn.1002-6819.2011.02.031

Article submitted: April 15, 2019; Peer review completed: May 26, 2019; Revised version received: May 28, 2019; Accepted: May 29, 2019; Published: June 5, 2019. DOI: $10.15376 /$ biores.14.3.5777-5787 